\title{
XXVI. Analytical proof of the parallelogram of forces
}

\section{T.H. Pratt}

To cite this article: T.H. Pratt (1849) XXVI. Analytical proof of the parallelogram of forces, Philosophical Magazine Series 3, 34:228, 201-202, DOI: 10.1080/14786444908646208

To link to this article: http://dx.doi.org/10.1080/14786444908646208

曲 Published online: 30 Apr 2009.

Submit your article to this journal $\llbracket$

Џll Article views: 2

Q View related articles $\sqsubset$ 
and as no other apparatus is required than our eyes and the objects of our inspection, it would seem that they were ensily made. But it requires rather an acquired power over the organs of vision to be readily successful. Sir David Brewster applied "binocular" convergence upon two figures, drawn side by side to superimpose one upon the other, and compare their exactness in point of size and form. I have extended the same operation to figures of unequal size, though of the same form. My son had just completed a half-size copy of a drawing representing an Arab on horseback, the correctness of which had been questioned. It was evident that, being placed at distances proportionate to their size, the images of the original and copy on the retina would be equal when a consistent illusive image might be obtained by convergence. The original was hung on the wall, and the half-size copy suspended at about half the distance fiom the observer, at such an angle that one could be fully seen beside the other. I converged or superimposed the images, and found them so nearly to coincide, that the common ontline was merely elegantly softened by the inequalities. In this experiment it appeared as if the eye, when the figures did not exactly coincide, had some power to complete the work or conceal the imperfections.

I have just succeeded in substituting a blank tablet for one of the pictures, and in tracing upon it with a pencil the illusive image converged from the other tablet. But this is not a very practicable method of copying pictures, requiring unusual command and steadiness of the optical axes for even the most moderate success in the operation.

XXVI. Analytical Proof of the Parallelogram of Forces. By T. H. Pratt.

To the Editors of the Philosophical Magazine and Journal. Gentlenen,

N my work on Mechanical Philosophy, I have given a proof of the Parallelogram of Forces which depends on the solution of the following functional equation,

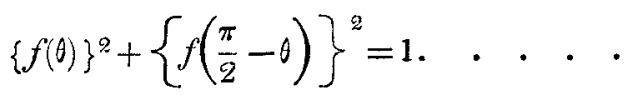

I there solved this equation indirectly. The following direct solution may be acceptable to some of your readers.

Put

$$
\{f(\theta)\}^{2}=\cos ^{2} \theta+(\cos \theta-\sin \theta) \phi(\theta)
$$


202 Suggestions for rendering a Meridian mark visible at Night. and the equation (1.) becomes after reduction

$$
\varphi(\theta)-\varphi\left(\frac{\pi}{2}-\theta\right)=0
$$

which is rendered identical by putting $\varphi(\theta)$ equal to any arbitrary function of $\sin 2 \theta$, as $\mathrm{H}(\sin 2 \theta)$.

Hence the most general solution of equation (1.) is

$$
\{f(\theta)\}^{2}=\cos ^{2} \theta+(\cos \theta-\sin \theta) F(\sin 2 \theta) . .
$$

In the application of this formula to the Parallelogram of Forces, we must make use of some condition that the function F may be determined; as mechanical experience shows it cannot remain arbitrary. Such a condition is the following: that if $\theta$ be increased by $\pi$, the resultant will obviously be the same as before in magnitude, but opposite in sign: this will therefore be the case with $f(\theta)$.

Put, therefore, $\pi+\theta$ for $\theta$ in (2.), and equate the two values of the square of the function (as they must be the same), and reduce, and we have

$$
\begin{gathered}
\cos ^{2} \theta+(\cos \theta-\sin \theta) F(\sin 2 \theta)=\cos ^{2} \theta-(\cos \theta-\sin \theta) F(\sin 2 \theta) ; \\
\therefore F(\sin 2 \theta)=0
\end{gathered}
$$

for all values of $\theta$.

Hence in the case of the Parallelogram of Forces,

$$
f(\theta)=\cos \theta \text { or }-\cos \theta \text {; }
$$

the latter is excluded, because when $\theta=0$, the resultant is the force itself, or $f(0)=1$.

Hence $f(\theta)=\cos \theta$ is the complete solution.

I am, Gentlemen,

Your obedient Servant,

Bombay, Dec. 14, 1848.

T. H. PratT.

XXVII. Suggestions for rendering a Meridian mark visible at Night. By N. S. HeINEKeN, Esq.

To the Editors of the Philosophical Magazine and Journal.

Gentlemen, Sidmouth, Feb. 14, 1849. GHOULD you deem the following suggestions likely to be $N$ of service, I shall be glad if you will give them a place in the Philosophical Magazine.

$$
\begin{aligned}
& \text { I am, Gentlemen, } \\
& \text { Respectfully yours, } \\
& \text { N. S. HeInekeN. }
\end{aligned}
$$

It occurred to me eleven years since, that platinum wire, rendered incandescent by the galvanic battery, might be ap- 